\title{
Pengaruh Abu Ampas Tebu Terhadap Kuat Tekan Beton Sebagai Bahan Tambah dalam Pembuatan Beton Normal
}

\author{
Eko Bagus Saputra'), Luky Indra Gunawan²), Hendramawat Aski Safarizki ${ }^{3)}$ \\ 1) 2) 3) Fakultas Teknik, Program Studi Teknik Sipil, Universitas Veteran Bangun Nusantara, Sukoharjo, J1. \\ Letjen Sudjono Humardhani, No.1, Jombor, Sukoharjo; Telp. 0271-593156. \\ Email:gustra1995@gmail.com
}

\begin{abstract}
Abstrak
Abu ampas tebu yang berasal dari PT. PG Madu Kisno merupakan limbah yang memiliki kandungan silikat cukup sebesar. Penelitian terhadap Abu ampas tebu dilakukan sebagai bahan tambah dengan prosentase sebesar $0 \%, 2.5 \%, 5 \%, 7.5 \%$, dan $10 \%$ terhadap berat semen. Penelitian ini bertujuan untuk mengetahui pengaruh Abu ampas tebu terhadap kuat beton.benda uji yang digunakan adalah silinder yang berdiameter $15 \mathrm{~cm}$ dan tinggi 30 $\mathrm{cm}$ pengujian dilakukan pada umur 28 hari. Penggunaan air untuk campuran beton dalam penelitian ini ditambahkan sebesar $1.068 \%$ untuk setiap prosentase Abu ampas tebu. Hasil penelitian menunjukan bahwa penambahan air sebesar $1.068 \%$ disetiap prosentase Abu ampas tebu yang ditambahkan menghasilkan nilai slump yang mendekati nilai slump beton normal. Pada kuat tekan beton Abu ampas tebu mengalami penurunan dibandikan dengan kuat tekan beton normal dengan hasil beton Abu ampas tebu mendapatkan kuat tekan tersebesar yakni 18,07 Mpa pada prosentase penambahan Abu ampas tebu 5\% dan beton normal mendapatkan kuat tekan sebesar 29,128 Mpa. Penggunaan Abu ampas tebu sebagai bahan tambah terhadap berat semen kurang begitu efektif.
\end{abstract}

Kata kunci: abu ampas tebu, kuat tekan, pengaruh, beton, bahan tambah

\begin{abstract}
Bagasse ash originating from PT. PG Madu Kisno is a waste that has a sufficient amount of silicate. Research on bagasse ash was carried out as an added material with a percentage of $0 \%, 2.5 \%, 5 \%, 7.5 \%$, and $10 \%$ of the weight of cement. This study aims to determine the effect of bagasse ash on concrete strength. The test object used was a cylinder with a diameter of $15 \mathrm{~cm}$ and a height of $30 \mathrm{~cm}$. The test was carried out at 28 days. The use of water for concrete mix in this study was added by 1,068\% for each percentage of bagasse ash. The results showed that the addition of water by 1,068\% in each percentage of added bagasse ash produced a slump value close to the normal concrete slump value. In the compressive strength of bagasse ash decreases compared with normal concrete compressive strength with the results of bagasse ash concrete gets the greatest compressive strength that is $18.07 \mathrm{Mpa}$ on the percentage increase of 5\% bagasse ash and normal concrete gets compressive strength of 29,128 MPa. The use of bagasse ash as an added material to the weight of cement is less effective.
\end{abstract}

Keywords: added material, bagasse ash, compressive strength, concrete, influence

\section{PENDAHULUAN}

Manusia tidak pernah jauh dari bangunan yang terbuat dari beton. Beton adalan material yang paling banyak digunakan di bumi ini. Dengan beton dapat dibangun bendungan, jalan raya, fondasi, bangunan gedung pencakar langit maupun basement.

Beton yang bermutu baik mempunyai beberapa kelebihan diantaranya mempunyai kuat tekan tinggi, tahan terhadap pengkaratan atau pembusukan oleh kondisi lingkungan, tahan aus, dan tahan terhadap cuaca (panas, dingin, sinar matahari, hujan). Beton juga mempunyai beberapa kelemahan, yaitu lemah terhadap kuat tarik, mengembang dan menyusut bila terjadi perubahan suhu, sulit kedap air secara sempurna, dan bersifat getas (Tjokrodimuljo, 1996).

Hal yang paling penting dalam pembuatan beton adalah beton harus mempunyai konsistensi yang baik, tetap kompak, tidak mengalami segregasi dan bleeding sehingga diperoleh beton dengan kualitas yang baik dan memadai. Kuat tekan beton selain dipengaruhi gradasi agregat, kualitas, maupun sifat agregat dengan cara pemadatan juga dipengaruhi oleh perbandingan antar air dan semen yang dipakai (faktor air semen). Semakin kecil faktor air semen yang digunakan maka akan menghasilkan kuat tekan yang semakin besar. Tapi sedikitnya jumlah air yang digunakan 
akan menyebabkan rendahnya kelecakan campuran yang berakibat sulit dikerjakan. Penggunaan bahan tambah pada pembuatan beton akan mempengaruhi kuat tekan dan sifat beton. Pada amaps tebu semakin tinggi variasi abu ampas tebu yang disubstitusi terhadap berat semen dengan nilai fas yang sama akan menurunkan tingkat workability dari beton (Akbar et al., 2019; Rompas et al., 2013).

Untuk memperoleh bahan struktur tidak harus menggunakan bahan utama saja tetapi juga bisa digunakan bahan-bahan tambahan atau penunjang. Bahan-bahan yang sudah tidak terpakai atau kata lain kita kenal dengan limbah/sampah mulai banyak diincar sebagai bahan penunjang, selain murah dan sebagai bahan sisa-sisa buangan diusahakan agar limbah tersebut bisa mempunyai kegunaan lain yang mampu meningkatkan kualitas pemanfaatan lebih baik.

Limbah tidak selamanya terbuang percuma. Kini, untuk membuat beton tak harus mengandalkan bahan-bahan beton konvensional yakni pasir, kerikil, dan semen. Berkat keuletan sejumlah peneliti, berbagai limbah bisa dimanfaatkan untuk itu. Memang tidak sembarang limbah bisa. Sebab, untuk dapat dijadikan bahan konstruksi ada syaratnya. Limbah itu tidak mengandung bahan berbahaya yang bisa mengganggu kesehatan, dan unsur-unsur yang dikandungnya tidak menimbulkan reaksi yang bertentangan dengan semen sebagai bahan perekatnya.

Ampas tebu (baggase ash) adalah campurandari serat yang kuat, yang mempunyai tingkat higroskopis yang tinggi, dihasilkan melalui penggilingan tebu. Ampas tebu sendiri merupakan hasil limbah buangan yang berlimpah dari proses pembuatan gula kurang lebih 30\% dari kapasitas giling (Widodo, 2017).

Abu ampas tebu memiliki kandungan yang samadengan bahan utama pembentuk semen portlandyaitu silika (SiO2) dan Ferrit (Fe2O3) sehingga dapatdijadikan sebagai pozolan yang selain menggantikan sebagian semen juga dapat meningkatkan kekuatantekan beton (Gemelly Katrina, 2014).

Potensi bagasse di indonesia menurut pusat penelitian perkebunan gula di indonesia (P3GI) tahun 2008, cukup besar dengan komposisi rata-rata hasil samping industri gula di indonesia terdiri dari limbah cair 52,9 persen, blotong 3,5 persen, ampas (bagasse) 32,0 persen,tetes 4,5 persen, dan gula 7,05 persen, serta abu 0,1 persen (Risky Kurnia.w, 2008).

Suhu pembakaran abu amapas tebu mempengaruhi terhadapat kuat tekan beton yang diiginkan. Semakin tinggi suhu pembakaran ampas tebu maka kuat tekan yang dihasilkan akan semakin menurun (Karimah and Wahyudi, 2016).

Berdasarkan kandungan silika ( $\mathrm{SiO} 2)$ dan ferrit (Fe2O3) yang cukup tinggi, abu ampas tebu juga dapat digunakan sebagai bahan tambah pada pembuatan beton, batako ringan dan pozzolan (bersifat semen) (Maulana Yusuf, Dede Suhendar, 2014).

Tujuan dilakukan penelitian ini adalah analisis pemanfaatan abu ampas tebu sebagai bahan tambah terhadap kuat tekan beton, dan analisis prosentase abu ampas tebu untuk mencapai kuat tekan yang optimal.

\section{METODE}

\section{Bahan dan Alat}

Agregat kasar dan agregar halus yaitu split dan pasir diperiksa dulu sebelum digunakan sebagai bahan penyusun campuran beton. Pengujian bahan untuk agregat halus meliputipemeriksaan gradasi agregat, kadar lumpur organik, kadar air, berat jenis dan penyerapan. Rencana campuran beton normal (mix design) dibuat dengan menggunakan perancangan beton menurut SNI 03-2834, 2000. Benda uji yang digunakan berbentuk silinder dengan ukuran tinggi $300 \mathrm{~mm}$, diameter $150 \mathrm{~mm}$ untuk uji kuat tekan.

\section{Metode penelitian}

Nilai kuat tekan beton didapatkan melalui tata cara pengujian standar menggunakan mesin uji dengan cara memberikan beban tekan bertingkat dengan kecepatan peningkatan beban tertentu dengan benda uji berupa silinder dengan ukuran diameter $150 \mathrm{~mm}$ dan tinggi $300 \mathrm{~mm}$. Selanjutnya benda uji ditekan dengan alat uji sampai pecah. Beban tekan maksimum pada saat benda uji pecah dibagi luas penampang benda uji merupakan nilai kuat desak beton yang dinyatakan dalam suatu Mpa atau kg/cm2. 
Tata cara pengujian yang umum dipakai adalah standar ASTM C 39. Rumus yang digunakan untuk untuk perhitungan kuat tekan beton adalah :

$f^{\prime} c=\frac{P}{A}$

Dengan $\mathrm{f}^{\prime} \mathrm{c}$ adalah kuat desak beton (MPa), $\mathrm{P}$ adalah beban maksimum $(\mathrm{N})$, dan $\mathrm{A}$ adalah luas penampang benda uji $\left(\mathrm{mm}^{2}\right)$

\section{HASIL DAN PEMBAHASAN}

\section{Hasil Uji Slump}

Pengujian slump bertujuan untuk mengetahui kekentalan adukan beton dari nilai slump agar dapat memenuhi syarat yang ditentukan. Kekentalan adukan beton dapat diperiksa dengan menguji beton segar sebelum dituang. Dengan cara diambil langsung dari mesin pengaduk menggunakan ember atau alat yang tidak menyerap air. Bila perlu adukan beton diaduk lagi sebelum pengujian slump. Pengujian ini dilakukan dengan menggunakan kerucut yang berdiameter atas $10 \mathrm{~cm}$, diameter bawah $20 \mathrm{~cm}$ dan tinggi $30 \mathrm{~cm}$. Penggunaan adukan beton yang terlalu kental maupun encer, dianjurkan pada batas yang ditunjukan dalam Tabel 1. Hasil uji slump test pada penelitian ini di tunjukan pada Tabel 2 .

Tabel 1 Nilai slump test untuk berbagai pekerjaan kontruksi (PBI 1971 N.I.-2)

\begin{tabular}{llcc}
\hline No & \multicolumn{1}{c}{ Elemen Struktur } & $\begin{array}{c}\text { Slump } \\
\text { Maks } \\
(\mathbf{c m})\end{array}$ & $\begin{array}{c}\text { Slump } \\
\text { Min } \\
(\mathbf{c m})\end{array}$ \\
\hline $\mathbf{1}$ & $\begin{array}{l}\text { Plat Pondasi, Pondasi } \\
\text { Telapak Bertulang }\end{array}$ & 12.5 & 5.0 \\
$\quad \begin{array}{l}\text { Pondasi telapak tidak } \\
\text { bertulang, kaison dan }\end{array}$ & 9.0 & 2.5 \\
$\quad \begin{array}{l}\text { konstrusi di bawah tanah } \\
\mathbf{3}\end{array}$ & $\begin{array}{l}\text { Plat (Lantai), Balok, Kolom } \\
\text { dan Dinding }\end{array}$ & 15.0 & 7.5 \\
$\mathbf{4}$ Jalan Beton Bertulang & 7.5 & 5.0 \\
$\mathbf{5}$ & Pembetonan Massal & 7.5 & 2.5 \\
\hline
\end{tabular}

Pengujian nilai slump diperlukan untuk mengetahui tingkat workabilitas adukan beton dengan adanya penambahan Abu Ampas Tebu.

Pada setiap beton yang ditambahkan bahan tambah Abu Ampas Tebu mengalami nilai Slump yang tidak jauh dari hasil Slump beton normal di karenakan Abu ampas tebu yang digunakan memiliki tingkat penyerapan air yang cukup besar maka dalam pembuatan beton yang ditambahkan abu ampas tebu harus ditambahkan air supaya mudah dalam pengerjaan. Pada pengujian slump dengan penurunan $2 \mathrm{~cm}$. Nilai ini tidak memenuhi persyaratan yang PBI 1971 N.I.-2 karena campuran Abu ampas tebu memiliki sifat menyerap air yang amat besar maka nilai Slump tidak dapat seperti persyaratan PBI 1971 N.I-2.

Tabel 2 Nilai slump test pada benda uji

\begin{tabular}{ccc}
\hline No & $\begin{array}{c}\text { Abu Ampas Tebu } \\
\text { yang ditambahkan }\end{array}$ & $\begin{array}{c}\text { Hasil Uji Nilai } \\
\text { Slump (cm) }\end{array}$ \\
\hline 1 & $0 \%$ & $2 \mathrm{~cm}$ \\
2 & $2.5 \%$ & $1.8 \mathrm{~cm}$ \\
3 & $5 \%$ & $1.5 \mathrm{~cm}$ \\
4 & $7.5 \%$ & $1 \mathrm{~cm}$ \\
5 & $10 \%$ & $1 \mathrm{~cm}$ \\
\hline
\end{tabular}

\section{Hasil Pengujian Beton}

Pengujian kuat tekan beton dilakukan pada beton umur 28 hari dengan menggunakan Compression Testing Machine (CTM) untuk mengetahui besar kuat tekan maksimum yang dapat ditahan oleh beton sampai beton retak atau hancur. Rekapitulasi hasil uji kuat tekan dapat dilihat pada Tabel 3.

Dari hasil uji kuat tekan beton umur 28 hari didapat kuat tekan beton rata-rata yakni dengan bahan tambah Abu ampas tebu $0 \%$ menghasikan kuat tekan beton 29,128 Mpa, untuk penambahan Abu ampas tebu 2,5\% menghasikan kuat tekan beton 16,27 Mpa, penambahan Abu ampas tebu 5\% menghasikan kuat tekan beton 18,07 Mpa, untuk penambahan Abu ampas tebu 7,5\% menghasikan kuat tekan beton 10,32 Mpa, dan penambahan $\mathrm{Abu}$ ampas tebu $10 \%$ menghasikan kuat tekan bton 12,21 Mpa. Maka dapat disimpulkan kuat tekan beton pada umur 28 hari dengan bahan tambah Abu ampas tebu pada penelitian ini menghasikan kuat tekan terbesar yakni 18,07 Mpa untuk kadar penambahan $5 \%$.

Untuk penambahan pembuatan beton abu ampas tebu dengan kadar 1\% Abu ampas tebu yang di tambahkan pada beton dibuat 1 buah benda uji tanpa menambahkan nilai fas atau air. Didapatkan nilai slump test yakni $0 \mathrm{~cm}$ serta nilai kuat tekan pada umur 28 hari sebesar 13.44 Mpa. Maka jika dibandingkan dengan penambahan Abu ampas tebu 2.5\% dan 5\% Pada beton. Hasil dari penambahan $1 \%$ Abu ampas tebu pada beton kuat tekan 
yang dihasilkan lebih cenderung turun dibandingkan $2.5 \%$ dan $5 \%$. Untuk hasil perbandingan kuat tekan beton dapat dilihat pada gambar 1 dan gambar 2 .

Tabel 3 Hasil uji kuat tekan

\begin{tabular}{|c|c|c|c|c|c|c|c|}
\hline No & $\begin{array}{c}\text { Kadar Bahan } \\
\text { Tambah Abu } \\
\text { ampas tebu }\end{array}$ & $\begin{array}{c}\text { Berat } \\
\text { Benda } \\
\text { Uji (Kg) }\end{array}$ & $\begin{array}{c}\text { Kode Benda } \\
\text { Uji }\end{array}$ & $\begin{array}{l}\text { Umur } \\
\text { Beton }\end{array}$ & $\begin{array}{c}\text { Kuat Tekan } \\
\mathrm{MPa}\end{array}$ & $\begin{array}{l}\text { Kuat Tekan } \\
\text { Rata-rata } \\
\text { (Mpa) }\end{array}$ & $\begin{array}{c}\text { Kuat Tekan } \\
\text { Rata-rata - } \\
\text { Deviasi ( Mpa) } \\
\end{array}$ \\
\hline \multirow{5}{*}{1} & \multirow{5}{*}{$0 \%$} & 13,3 & AAT . $0 \%$ & 28 & 22,58 & \multirow{5}{*}{29,128} & \multirow{5}{*}{34,42} \\
\hline & & 13,3 & AAT . $0 \%$ & 28 & 28,25 & & \\
\hline & & 13,25 & AAT . $0 \%$ & 28 & 30,47 & & \\
\hline & & 13,3 & AAT . $0 \%$ & 28 & 31,83 & & \\
\hline & & 13,25 & AAT . $0 \%$ & 28 & 32,51 & & \\
\hline \multirow{3}{*}{2} & \multirow{3}{*}{$2,50 \%$} & 13,3 & AAT $.2 .5 \%$ & 28 & 15,5 & \multirow{3}{*}{16,27} & \multirow{3}{*}{17,67} \\
\hline & & 13,28 & AAT $.2 .5 \%$ & 28 & 15,58 & & \\
\hline & & 13,4 & AAT $.2 .5 \%$ & 28 & 17,47 & & \\
\hline \multirow{4}{*}{3} & \multirow{3}{*}{$5 \%$} & 12,9 & AAT . $5 \%$ & 28 & 18,1 & \multirow{3}{*}{18,07} & \multirow{3}{*}{20,21} \\
\hline & & 13,1 & AAT . $5 \%$ & 28 & 16,56 & & \\
\hline & & 13,25 & AAT . $5 \%$ & 28 & 19,54 & & \\
\hline & & 12,6 & AAT $.7 .5 \%$ & 28 & 9,53 & \multirow{3}{*}{10,32} & \multirow{3}{*}{11,78} \\
\hline \multirow[t]{2}{*}{4} & $7,50 \%$ & 12,7 & AAT $.7 .5 \%$ & 28 & 9,837 & & \\
\hline & & 12,8 & AAT $.7 .5 \%$ & 28 & 11,57 & & \\
\hline \multirow{3}{*}{5} & & 12,4 & AAT . $10 \%$ & 28 & 16,62 & \multirow{3}{*}{12,21} & \multirow{3}{*}{17,49} \\
\hline & $10 \%$ & 12,7 & AAT . $10 \%$ & 28 & 9,19 & & \\
\hline & & 12,7 & AAT $.10 \%$ & 28 & 10,83 & & \\
\hline
\end{tabular}

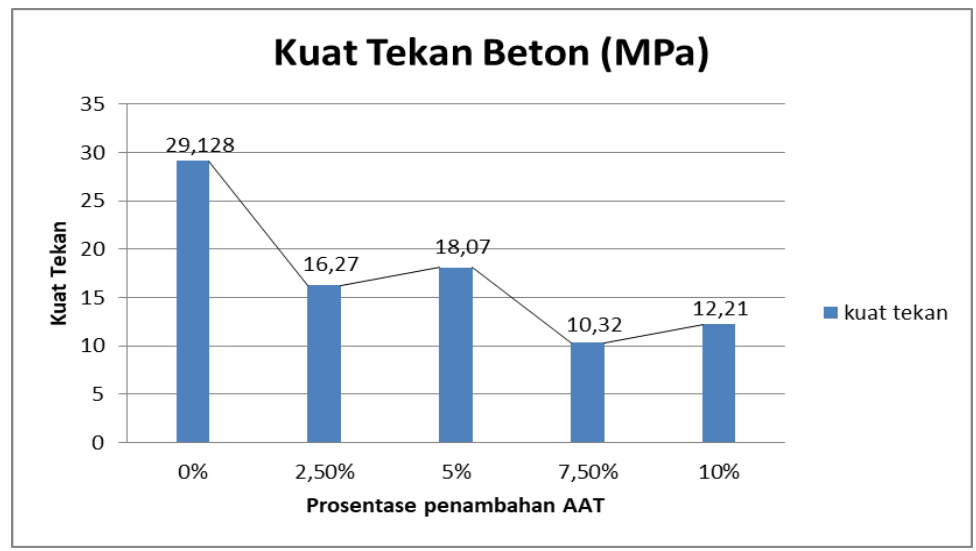

Gambar 1. Grafik kuat tekan beton AAT 0\%, 2.5\%, 5\%, 7.5\%, 10\%

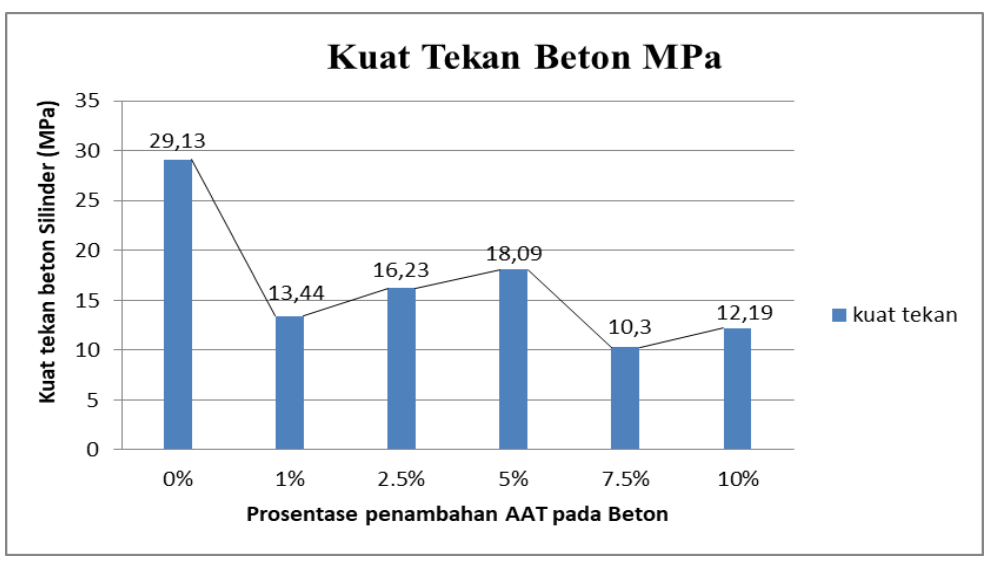

Gambar 2 Grafik kuat tekan beton AAT 0\%, 1\%, 2.5\%, 5\%, 7.5\%, 10\% 


\section{SIMPULAN}

Dari data hasil pengujian, analisis data, dan pembahasan Beton Normal dangan bahan tambah Abu ampas tebu sebesar 0\%, 2.5\%, $5 \%, 7.5 \%, 10 \%$, dapat ditarik kesimpulaan bahwa kuat tekan beton dengan Abu ampas tebu yang ditambahkan dari berat semen menurun dibandingkan dengan kuat tekan beton normal. Hal ini terjadi dikarenakan beton yang ditambahkan Abu ampas tebu mengalami Penurunan kuat tekan disebabkan reaksi pozzolan dengan $\mathrm{Ca}(\mathrm{OH} 2)$ belum terjadi secara sempurna pada umur 28 hari, sehingga kontribusinya terhadap kekuatan beton membutuhkan waktu yang lebih panjang.

\section{UCAPAN TERIMAKASIH}

Ucapan terima kasih terutama ditujukan kepada laboratorium Bahan Bangunan Universitas Veteran Bangun Nusantara Sukoharjo.

\section{DAFTAR PUSTAKA}

Akbar, I., Djauhari, Z., Suryanita, R., 2019. Pengaruh Penambahan Abu Ampas Tebu Terhadap Sifat Mekanik Beton Pada Campuran Beton Normal. Jom FTEKNIK 6, 1-8.

Gemelly Katrina, 2014. Pemanfaatan Limbah Kulit Kerang sebagai Subsitusi dan Abu Ampas Tebu Sebagai Subsitusi Semen pada Campuran Beton Mutu K-225. J. Tek. Sipil dan Lingkung. 2, 308-313.

Karimah, R., Wahyudi, Y., 2016. Pemakaian Abu Ampas Tebu Dengan Variasi Suhu Sebagai Substitusi Parsial Semen Dalam Campuran Beton. J. Media Tek. Sipil 13, 167-173.

https://doi.org/10.22219/jmts.v13i2.2563

Maulana Yusuf, Dede Suhendar, E.P.H., 2014. Studi Karakteristik Silika Gel Hasil Sintesis Dari Abu Ampas Tebu Dengan Variasi Konsentrasi Asam Klorida. Junal Kaji. Islam. Sains, dan Teknol. VIII, 1628.

Rompas, G.P., Pangouw, J.D., Pandaleke, R., Mangare, J.B., 2013. Pengaruh Pemanfaatan Abu Ampas Tebu Sebagai Substitusi Parsial Semen Dalam Campuran Beton Ditinjau Terhadap Kuat Tarik Lentur Dan Modulus Elastisitas. J. Sipil Statik 1, 82-89.

SNI 03-2834, 2000. Tata Cara Pembuatan Rencana Campuran Beton Normal. Badan Stand. Nas.

Widodo, A., 2017. Pengaruh Penambahan Abu Ampas Tebu (Bagasse Ash) pada Kuat Tekan dan Kuat Lentur Struktur Balok. J. Rekayasa Tek. Sipil 3, 105-111. 